\title{
EESTI VIIPEKEELE TRANSKRIPTSIOONIST
}

\section{REIGINA TOOM, MONIKA TRÜKMANN, LIIVI HOLLMAN}

Ülevaade. Eesti viipekeel on keel, mida kasutab ligikaudu 1500 Eestis elavat kurti. Sarnaselt teistele viipekeeltele puudub ka eesti viipekeelel kirjalik vorm. Eesti viipekeele uurimise ajaloos on viibete noteerimisel kasutatud erinevaid süsteeme. Käesoleva süsteemi loomisel on toetutud eelnevatele ülevaadetele ja uurimustele. Eeskujuks on võetud W. Stokoe poolt loodud notatsioonisüsteem ja selle edasiarendused. Süsteem toetub eesti viipekeele kiroloogiale, eesti sõrmendtähestikule ning numbrite süsteemile ja koosneb 38 käekujukireemist, 26 viipe artikulatsiooni kohast ning 26 liigutusest. Täpsustavate kireemidena sisaldab süsteem peopesa ja sõrmede orientatsiooni sümboleid. Viibete ülesmärkimine toimub vastavalt algoritmile järjestuses: käevorm, peopesa ja sõrmede orientatsioon, viipe moodustuskoht ja liigutus. Esitatakse ka mõned reeglid ja põhimõtted eesti viipekeele semantika, morfoloogia ja süntaksi kirjeldamiseks eesti keeles.

Võtmesõnad: viipekeel, keeleala uurimine, meetodid ja vahendid, eesti viipekeel

Viipekeel (sign language) on kurtide inimeste peamise suhtlemisvahendina nende kultuuri oluliseks osaks. Seejuures moodustavad viiplevad kurdid igas ühiskonnas keelelise vähemusrühma. Igal maal kasutatakse oma viipekeelt (Eestis eesti viipekeel, Rootsis rootsi viipekeel jne). Viipekeeled on visuaal-ruumilises keskkonnas toimivad keeled, erinevalt verbaalsetest keeltest, mis realiseeruvad auditiiv-verbaalses keskkonnas. Viipekeelte primaarseks vahendiks on viiplemine ning keeleline signaal tekitatakse keha, käte ja näo samaaegse liikumisega viiperuumis. Eesti viipekeelt hakati uurima alles 20. sajandi kaheksakümnendatel aastatel (Laiapea jt 2003: 27). Praegu kuulub see maailmas ametlikult tunnustatud keelte hulka, olles registreeritud maailma keelte andmebaasis ${ }^{1}$ (rahvusvaheline kood: ESO).

1 Vt Ethnologue http://www.ethnologue.com/show_language.asp?code=eso (30.1.2006) 


\section{Viipekeelte kiroloogia}

20. sajandi kuuekümnendatel aastatel tõi William Stokoe $^{2}$ esimest korda viipekeeled lingvistide huviorbiiti. Koos uurijate C. Casterline’i ja G. Cronebergiga tegi ta 1965. a esimese katse analüüsida ameerika viipekeelt foneemi tasandil. Nende töö on märkimisväärne eelkõige alljärgnevatel põhjustel:

(a) tuvastati verbaalsete keelte fonoloogilise ülesehitusega sarnanev organiseeritus ameerika viipekeele viibetes;

(b) ameerika viipekeele viibete fonemaatilisel analüüsil toetuti kontrastidele, mille tulemusena tulid esile viibete erisused. Seega oli viibete koostiselementidel foneemi staatus, kus ühe elemendi asendamine teisega tõi kaasa viipe tähenduse muutumise või kadumise;

(c) tõestati, et ameerika viipekeele viipeid on võimalik kirjeldada vaid kindla arvu käekuju-, liigutus- ja kohafoneemide abil (Moy 1990: 346). Hiljem on viibete ülesehitust uurinud mitmed autorid. S. Liddelli ja R. Johnsoni väitel teostub viibe eelkõige kompleksis hoid-liigutus-hoid (hold-movement-hold). Viibe võib alata hoiuga ning lõppeda liigutusega või vastupidi, samuti koosneda ainult hoiust (Liddell, Johnson 2000 [1989], viidatud Laiapea 1992: 2105 järgi).

Viiped jagunevad ühe- ja kahekäeviibeteks. Viimaseid saab omakorda jagada sümmeetrilisteks (mõlemad käed liiguvad/paiknevad teineteise suhtes peegelpildis) ning mittesümmeetrilisteks (üks käsi on paigal, teine liigub selle suhtes). Käte koostööd reguleerivad R. Battisoni poolt 1978. a kirjeldatud sümmeetria- ja dominantsireeglid (Boyes Braem 1995: 27).

Praegu on verbaalsete keelte ja viipekeelte võrdlemisel jõutud arusaamisele, et ka viipekeeled on hierarhilised, järgides verbaalsetele keeltele omaseid kindlaid keeletasandeid. Hierarhilise keelesüsteemi väikseima tähendust eristava vormiüksuste tasandi moodustavad foneemid, mis verbaalsetes keeltes avalduvad lineaarses järjestuses.

W. Stokoe võttis 1970-ndatel viipe väikseimate tähendust kandvate ühikute tähistamiseks kasutusele termini kireem (ingl cherem < kr cheir 'käsi') ja nimetas viibete struktuuri ja korraldust uuriva teadusharu kiroloogiaks (ingl cherology, ka chirology). Ta eristas ameerika viipekeeles kolme simultaanselt esinevat kireemitüüpi.

1. Käekuju ehk käevorm (designator) - artikuleerib ehk tekitab keelelise signaali.

2. Koht (tabula) - koht, kus toimub artikulatsioon. Kohaks võib olla neutraalruum, s.o koht viipleja ees, samuti keha eri piirkonnad.

3. Liigutus (signation) - artikulatsioon, liikumine (sirge, kaarjas, spiraalne, avanev, sulguv jne) (Valli, Lucas 2000: 26).

Käekuju juures eristas W. Stokoe ka peopesa ja sõrmede orientatsiooni (asendit) keha suhtes, mille muutus tingib viipe tähenduse muutuse. Hiljem on peopesa orientatsiooni käsitletud eraldiseisva ehk neljanda kireemina. S. Liddell ja R. Johnson täiendasid 1980-ndatel Stokoe-süsteemi veelgi, võttes viibete analüüsil arvesse ka mittekäelisi signaale (näoilme, suupilt jmt) kui viipe koostisosi (Liddell, Johnson 2000 [1989]: 272). 
Märkimist väärib, et hulk hilisemaid uurijaid (S. Liddell, R. Johnson, C. Valli, C. Lucas, W. Sandler jt) on leidnud, et kireemide simultaansus ei näi kehtivat kõigi viibete puhul. Järjestikuliselt esitatavate kireemidega on tegemist juhul, kui viibe sisaldab mitut sama tüüpi kireemi (nt liigutust, käekuju). Nendel juhtudel on tegemist kireemidega, mis ilmnevad üksteise järel kindlas järjekorras (Moy 1990: 246-247). Kuna kireemidel on tähendust eristav funktsioon, siis neid kombineerides saab moodustada uusi viipeid ning ühe kireemi muutus kutsub esile viipe tähenduse muutuse. Seega oleks teoreetiliselt võimalik moodustada lõpmatu hulk viipeid, kuid nii nagu verbaalsetes keeltes pole sallitud kõik foneemikombinatsioonid, on ka viipekeeltes teatud kireemide koosesinemise piiranguid.

Viipekeelte uurimisel on selgunud, et viipekeelte kireemide arv on erinev, kusjuures aja jooksul see muutub. See võib tuleneda sellest, et keeleuurimismeetodeid ja uurimistulemusi on erinevalt tõlgendatud, aga ka keele loomulikust muutumisest ökonoomsuse suunas. Nii eristas W. Stokoe ameerika viipekeeles 19 käekuju, 12 artikulatsioonikohta ja 24 liigutust, mis ühtekokku moodustavad 55 kireemi (Stokoe jt 1976: 245-246; Valli, Lucas 2000: 27). Sandler esitab samuti 55 kireemi, kuid temal jagunevad need teisiti: 21 käekuju, 12 artikulatsioonikohta ning 22 liigutust (Sandler 1989: 53-54).

\section{Viipekeelte transkriptsioonisüsteemid}

Viibete ülesmärkimiseks on erinevatel aegadel ja mitmetes maades välja töötatud hulk transkriptsioonisüsteeme. Viipekeelte transkriptsioonisüsteemi läheb eelkõige vaja viipekeelte ülesmärkimiseks nende kirjeldamisel ja uurimisel. Kuna viiped on liikuvad ja viipemärgi mõistmine staatilise pildina on keeruline, siis on viipe täpseks tajumiseks, kirjeldamiseks ning analüüsimiseks vajalik neid sümbolite abil üles märkida.

Kuna viipekeelne kogukond on ühiskonnas keelelises vähemuses, valdab suurem osa kurte kohaliku viipekeele kõrval ka suuremal või vähemal määral vastava ühiskonna dominantkeele kirjalikku vormi. Sellest tulenevalt puudub otsene vajadus viipekeele kirjaliku vormi kujunemise järele (viimane annaks võimaluse suhelda üksnes viipekeelt valdavate inimestega). Ka loob infotehnoloogia areng järjest suuremaid võimalusi viipekeelse teksti salvestamiseks ja edastamiseks.

Ükski transkriptsioonisüsteem ei ole leidnud nii laiaulatuslikku kasutuselevõttu, et seda võiks pidada universaalseks ja ainuõigeks (Senghas, Monaghan 2002: 86). Järgnevalt tutvustatakse neist mõnda.

\subsection{William C. Stokoe notatsioonisüsteem}

W. Stokoe loodud notatatsioonisüsteem toetub tema poolt kirjeldatud viipe kiroloogilisele ülesehitusele. Stokoe-süsteemis märgitakse kireemid üles ranges järjekorras: esmalt viipe moodustamise koht (tabula ehk T), seejärel käekuju (designator ehk D) ja liigutus (signation ehk S). Seega on Stokoe-süsteemis järgmised algoritmid: ühekäeviibe $-\mathrm{TD}^{\mathrm{s}}$, kahekäeviiped $-\mathrm{TDD}^{\mathrm{s}}$, kahe erineva liigutusega viibe $-\mathrm{TD}^{\mathrm{ss}}$. 
Kõiki ameerika viipekeele käekujusid, liigutusi ja viipe moodustuskohti tähistavad Stokoe-notatsioonisüsteemis vastavad sümbolid. Käekujude tähised on üle võetud ameerika viipekeele numbrite süsteemist ja sõrmendtähestikust, alaindeksid tähistasid peopesa ja sõrmede orientatsiooni, millest hiljem sai Stokoe-süsteemi edasiarendustes iseseisev tähendust eristav parameeter (Valli, Lucas 2000: 25-27).

\subsection{Notatsioonisüsteem SignWriting}

Süsteem SignWriting loodi 1974. a Taani Kopenhaageni Ülikoolis. Kuivõrd viipekeeli oli just hakatud keelena tunnustama, tekkis teadlastel vajadus uuritavaid viipeid ka kirja panna. Audioloogi ja taani viipekeele uurija Lars von der Liethi tähelepanu äratas Valerie Suttoni süsteem DanceWriting, mis oli loodud tantsuliigutuste ülestähendamiseks jooniste abil. Viimast hakati kohandama viibete kirjeldamiseks, ning uue süsteemi nimeks sai SignWriting. ${ }^{3}$ Kuna süsteemi ülesehitus sarnaneb piktogrammidele ning viipe ülesmärkimisel antakse keha ja käte orientatsioon viipe sooritamisel edasi joonisena (mis võimaldab väljendada ka näomiimikat), saab seda kasutada mis tahes viipekeele puhul. SignWriting-süsteemil ei ole mingeid seoseid teiste transkriptsioonisüsteemidega ning seda on lingvistilistes uurimustes keeruline kasutada, sest süsteemi aluseks on viipe kui terviku väline vorm, mitte viipe kiroloogiline ülesehitus.

\subsection{Hamburgi notatsioonisüsteem}

Hamburgi notatsioonisüsteem (lühend HamNoSys) loodi Saksamaal, Hamburgi Ülikoolis (Prillwitz, Wudtke 1989). Kuna tegemist on Stokoe-süsteemi edasiarendusega, siis on seda teaduses hoopis laialdasemalt kasutatud kui SignWritingsüsteemi. Süsteemis on kokku ligikaudu 200 sümbolit, mis tähistavad eri käekujusid, peopesa ja sõrmede orientatsioone, viipe moodustuskohti ja liigutusi. Sümbolid märgitakse üles kindlas järjestuses: käevorm, peopesa ja sõrmede orientatsioon, koht ja liigutus.

Kireemide (nt käekujude) tähistused ei toetu nimetatud süsteemis mitte sõrmendtähestikule, vaid ikoonilisusele (tegemist on graafiliste märkidega). ${ }^{4}$ Just see võimaldab HamNoSys-süsteemi kasutada rahvusvaheliselt, sealhulgas ka eri viipekeelte kirjeldamiseks ja võrdlemiseks. Kuigi süsteem on täpne ja põhjalik, on teda siiski raske tarvitada just graafiliste märkide tõttu, sest see eeldab vastavate programmide olemasolu.

\section{Eesti viipekeele transkriptsioon}

Esimesed katsed eesti viipekeele viibete ülesmärkimiseks tehti 1990-ndate alguses. Eestis tegeles toona eesti viipekeele uurimisega kaks töörühma: Tartu Ülikoolis tegutsev keelelaboratoorium Regina Toome juhendamisel (1989-1990) ja Porkuni Kurtide Koolis töötav Viipekeele Keskus Vahur Laiapea juhendamisel (1991-1992). Kumbki töörühm kujundas välja oma viibetes kasutatavate käevormide tabeli ja viibete ülesmärkimise süsteemi (vt joonis 1 ja joonis 2). 


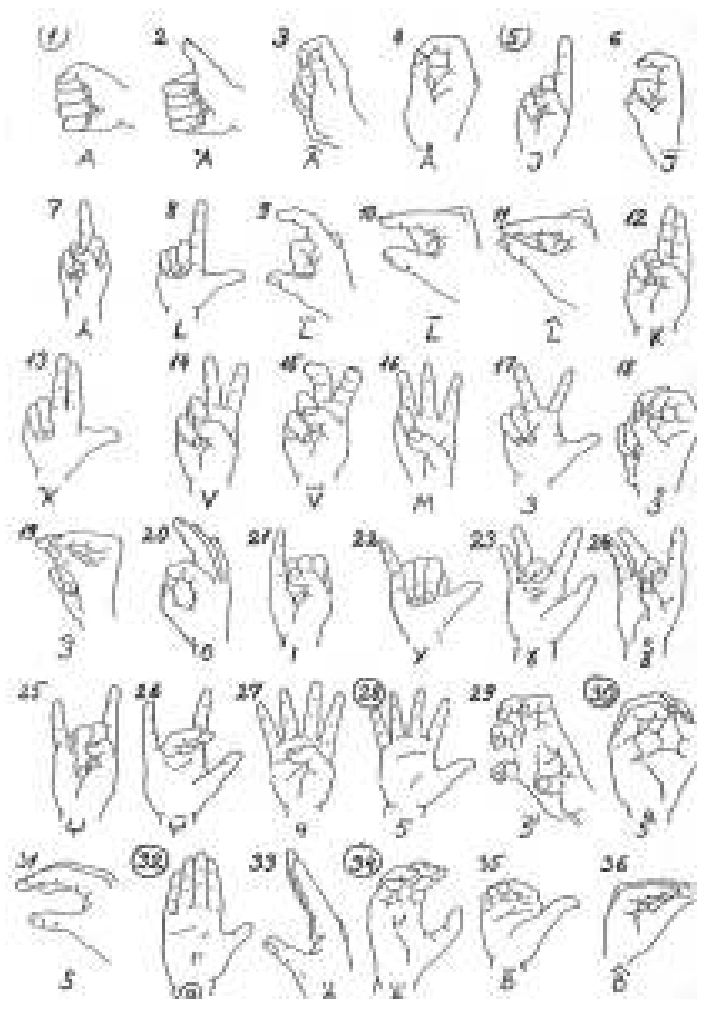

Joonis 1. Tartu Ülikooli töögrupi poolt esitatud käekujud

TÜ keelelaboris võeti aluseks M. Brennani (1990) kireemide (käekuju, koht ja liigutus) tähistamise sümbolid ja T. Rissase (1985: 18) viiperuumi piirkondade jaotus. Keelelabori uurimuste tulemusena esitati 36 käekujukireemi, 23 kohakireemi ja 29 liigutuskireemi. Viibete analüüsimisel võeti arvesse peopesa ja sõrmede orientatsiooni ning käte omavahelist suhet. Viiped märgiti üles kolme valemi abil, milles kasutati kireemide kirjeldamiseks loodud sümboleid. Valemid kirjeldasid: a) ühekäeviibet, b) kahekäeviibet, kus mõlemad käed on aktiivsed, c) kahekäeviibet, kus passiivne käsi on viipe sooritamise kohaks. Nimetatud eesti viipekeele viibete transkribeerimise süsteem siiski laialdaselt kasutusele ei läinud. Sümbolid ja valemid võeti kasutusele ainult keelelaboratooriumi töös ning õppe-eesmärgil eesti viipekeele õpetamisel TÜ-s.

Eesti viipekeelt ja viipeid uurides on kireemides täheldatud muutusi. Nii selgus näiteks TÜ eripedagoogika osakonnas bakalaureusetöö raames läbi viidud uurimusest (Püvi 2005), mille eesmärk oli välja selgitada kirjalikult fikseeritud 383 viipes esinevad kireemid, et 383 viipes esines kokku 80 kireemi: 34 käekuju, 19 moodustuskohta ning 27 liigutust. Viibete väikese arvu tõttu ei saa teha laiaulatuslikke järeldusi, kuid esialgsete andmete järgi on siiski huvitav tuua välja mõned tähelepanekud. Ilmnes, et TÜ keelelabori 36-st käekujust oli Püvil esindatud 33 ja puudus 3 käevormi. Samas esines uuritud viibetes kaks käekuju, mis TÜ ülevaates puudusid. Porkuni Viipekeele Keskuse 38-st käekujust oli E. Püvil 


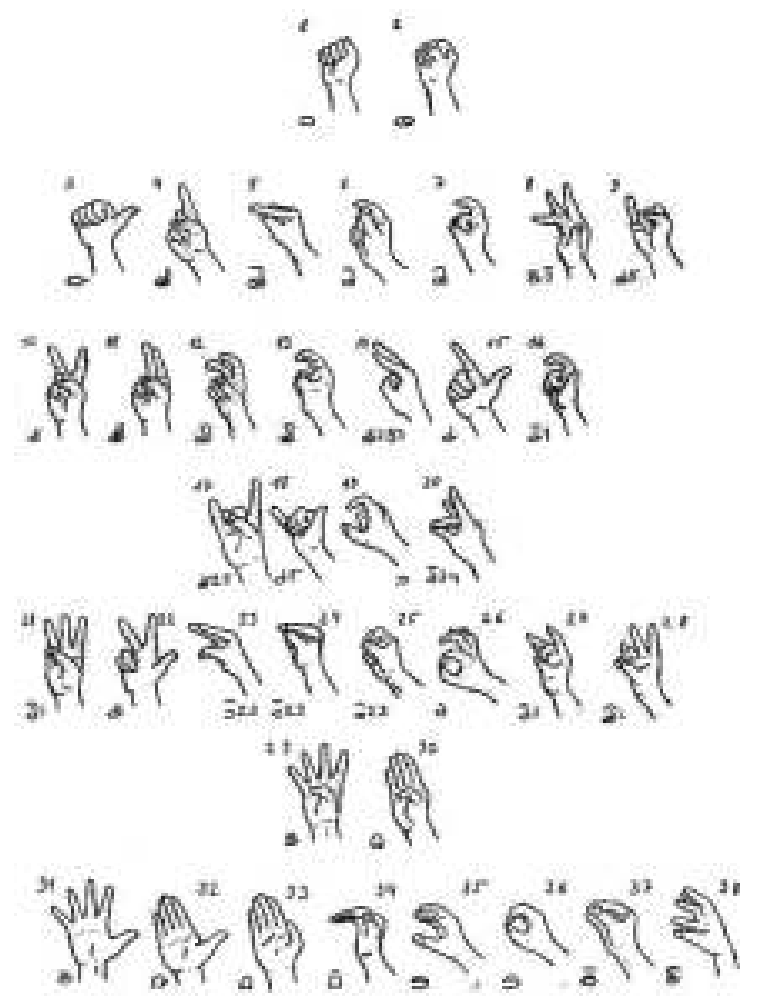

Joonis 2. Porkuni Kurtide Kooli Viipekeele Keskuse poolt esitatud käekujud

olemas 31 ning puudus 7 käevormi. Kolm käevormi ei kajastu Porkuni Viipekeele Keskuse ülevaates (Püvi 2005: 31). Töö selles uurimisvaldkonnas jätkub.

\subsection{Eesti viipekeele kireemid ja nende tähistamiseks kasutatavad sümbolid}

Seoses uute eesti viipekeele uurimustega Tartu Ülikoolis ja Eesti Keele Instituudis (Monika Trükmann (2006) "Ajasuhete väljendamine eesti viipekeeles”, TÜ magistritöö; Liivi Hollman "Värvinimed eesti viipekeeles”, TÜ doktoriuurimus) tekkis 2005. a vajadus üle vaadata olemasolevad eesti viipekeele kireemide tabelid ning kohandada transkriptsioonisüsteemi nii, et seda oleks võimalikult lihtne kasutada mis tahes arvutiprogrammis. Siinkohal pakume välja hüpoteetilise kogumi eesti viipekeele kireeme ning neid tähistavaid sümboleid.

Eesti viipekeele kireemide kirjeldamisel ja ülesmärkimisel toetume TÜ keelelaboratooriumi varasematele töödele, uute sümbolite väljatöötamisel oleme lähtunud arvutiga töödeldavuse põhimõttest. Transkribeerimisel soovitame kasutada kirjastiili Arial. Kireemide tähistuste juures järgime Stokoe-notatsioonisüsteemi edasiarendusi, kuid viipe ülesmärkimise algoritmis oleme aluseks võtnud pigem HamNoSys-i ülesehituse. Varem välja töötatud sümbolite kasutamise reegleid ja 


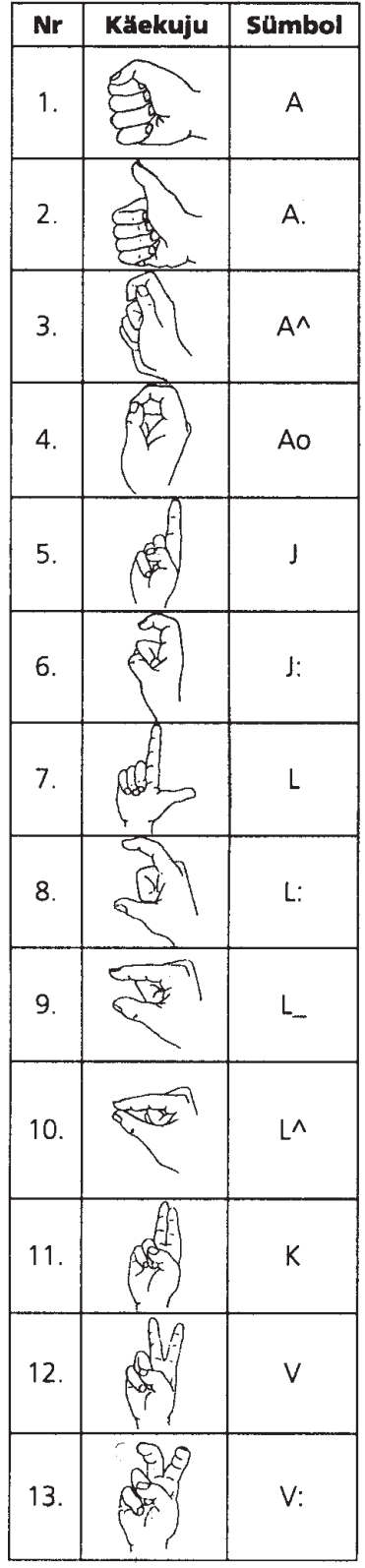

\begin{tabular}{|c|c|c|}
\hline $\mathbf{N r}$ & Käekuju & Sumbol \\
\hline 14. & & $M$ \\
\hline 15. & & 3 \\
\hline 16. & & 30 \\
\hline 17. & & $3^{\wedge}$ \\
\hline 18. & & 0 \\
\hline 19. & & 1 \\
\hline 20. & & $Y$ \\
\hline 21. & & $\mathrm{Q}$ \\
\hline 22. & & $R$ \\
\hline 23. & & $N$ \\
\hline 24. & & 0 \\
\hline 25. & & O_ \\
\hline 26. & त्र & 4 \\
\hline
\end{tabular}

Joonis 3. Võimalikud eesti viipekeele käekujukireemid ja nende tähistused. Punkt (.) numbri või sõrmendi järel tähistab pöidla eemaldumist labakäest ning punkt (.) sõrmendi ees pöidla lähenemist labakäele, koolon (:) sõrmede kõverdumist,

väike o (o) pöidla ja kõverdatud sõrmede seost, katus (^) pöidla ja sirgete sõrmede seost ning alakriips (_) sõrmede täisnurkset kõverdamist labakäe suhtes, ilma ühenduseta pöidlaga

\begin{tabular}{|c|c|c|}
\hline $\mathbf{N r}$ & Käekuju & Sümbol \\
\hline 27. & & 5 \\
\hline 28. & & 5: \\
\hline 29. & & $E$ \\
\hline 30. & & $B$ \\
\hline 32. & & $B_{-}$ \\
\hline 33. & & 5 \\
\hline 34. & & F. \\
\hline 35. & & $D$ \\
\hline 36. & & $\mathrm{~K}:$ \\
\hline 37. & & K. \\
\hline 38. & & $\wedge$ \\
\hline 39. & & $\mathrm{Aa}$ \\
\hline 40. & & $\mathrm{Bb}$ \\
\hline 41. & & .B \\
\hline
\end{tabular}


valemeid oleme täiendanud R. Sutton-Spence'i ja B. Woll'i (2003) kirjeldatud viibete ja viipekeelsete lausete transkribeerimisreeglite järgi, mis võimaldab viipe moodustamise detailse transkriptsiooni kõrval märkida üles ka nende tähendust.

Senistele uurimustulemustele toetudes pakume siinkohal välja 38 käekujukireemi (joonis 3). Siiski, käekujud, mis joonisel 3 on tähistatud numbritega 37 (K.) ja 38 (八), esinevad mõlemad teadaolevalt vaid ühes viipes (K. - TULISTAMA; $\bigwedge-$ TANK). Võib oletada, et need käekujukireemid on eesti viipekeelest kadumas. Käekujud 39-41 on esitatud variantidena, st need küll esinevad eesti viipekeeles, kuid neil ei ole tähendust eristavat funktsiooni. ${ }^{5}$ Käekujukireemide aluseks on (sarnaselt Stokoe-süsteemile) eesti viipekeele sõrmendtähestik ja eesti viipekeele numbrite süsteem.

Sõrmede liikumist viipe moodustamisel tähistatakse käekujuga koos: tärn $\left(^{*}\right)$ käekujusümboli järel tähistab sõrmede edasi-tagasi liikumist, laineline kriips ( ) sõrmede kõverdamist (nt $\mathrm{J}$ : käekuju moodustamine $J$ käekujust, V: käekuju moodustamine V käekujust), trellid (\#) sõrmede sirgelt kokku liikumist (nt D käekuju moodustamine B käekujust) ja suur $u$ (U) sõrmede avanemist (nt 5 käekuju moodustamine E käekujust), laineline kriips koos trellidega ( \#) märgi ees tähistab sõrmede kõverdumist ja sulgumist (A käekuju moodustamine 5 käekujust).

Peopesa ja sõrmede orientatsioon on tähendust eristava funktsiooniga kasutusel ka eesti viipekeeles. Käsitletavas süsteemis soovitame eesti viipekeele transkribeerimisel märkida peopesa ja sõrmede orientatsioon ära teisel kohal, kohe pärast käekujukireemi tähistust tabelis 1 märgitud sümbolite abil.

Tabel 1. Peopesa ja sõrmede orientatsioon

\begin{tabular}{|c|c|c|}
\hline Sümbol & Orientatsioon & Näited \\
\hline \multicolumn{3}{|c|}{ A. Peopesa } \\
\hline$\wedge 1$ & üles & ELAMA \\
\hline V1 & alla & MAA, PUHAS (domineeriva käe orientatsioon) \\
\hline |"1 & enda poole & TAHTMA, EMA \\
\hline 11 & endast eemale & VIIMA, HOMMIK \\
\hline$(1$ & paremale & OLEMA \\
\hline$) 1$ & vasakule & TEE (parema käe orientatsioon) \\
\hline \multicolumn{3}{|c|}{ B. Sörmed } \\
\hline$\wedge 2$ & üles & EMA, HOMMIK \\
\hline V2 & alla & TAGASIHOIDLIK \\
\hline |"2 & enda poole & SÖÖMA \\
\hline 2 & endast eemale & ÕPETAMA \\
\hline 2 & paremale & PIDU (parema käe orientatsioon) \\
\hline$(2$ & vasakule & PIDU (vasaku käe orientatsioon) \\
\hline
\end{tabular}

Kolmandana on valemis märgitud viipe moodustuskoht. Kohakireemidena pakume välja 26 erinevat kohta, mida tähistatakse tabelis 2 märgitud sümbolitega. 
Tabel 2. Kohakireemid

\begin{tabular}{|c|c|c|}
\hline Sümbol & Viipe moodustuskoht & Näited \\
\hline /O/ & neutraalruum & KOOL \\
\hline 0 & nägu & NEEGER \\
\hline $\mathrm{O} \wedge^{\wedge}$ & pealagi & (kuninga) KROON \\
\hline O- & laup & PALAV \\
\hline $\mathrm{O}^{\prime}$ & meelekoht & MÕTLEMA \\
\hline (o) & silm & SININE, ILM \\
\hline o & nina ots & JUST \\
\hline $0<$ & nina külg & JUUNI \\
\hline $\mathrm{O}_{-}$ & nina all & MEES \\
\hline$U$ & lõug & ISA \\
\hline$U_{-}$ & Iõua all & OKTOOBER \\
\hline$)$ & põsk & PUNANE \\
\hline$)^{*}$ & kõrv & KUULMA \\
\hline $\mathrm{Y}$ & kael & KASK \\
\hline$y<$ & kaela külg & LIHA \\
\hline [] & rindkere & TEATER \\
\hline$]$ & vasak rind / külg & ARMASTAMA \\
\hline[ & parem rind / külg & FIRMA \\
\hline L- & õlg & VÕIMLEMA \\
\hline $\mid=/$ & kõht & MAGU \\
\hline$\backslash$ & puus & DIREKTOR \\
\hline$?$ & reis & KOER \\
\hline$\|$ & õlavars & POLIKLIINIIK, ARST \\
\hline $\mid=$ & küünarvars & MIILITS \\
\hline$\|$ & käelaba & PUHAS \\
\hline $\mathrm{s}$ & käe selg & VALGE \\
\hline |k & käe külg & PRUUN \\
\hline
\end{tabular}

Käte liikumise markeerimiseks viipe moodustamisel oleme kasutusele võtnud tabelis 3 märgitud sümbolid. Sõrmede liikumist soovitame näidata koos käekujukireemi sümboliga. Kuna nii sõrmede kui käe liikumise puhul oleme püüdnud rakendada samade sümbolite kasutamist, on eriti juhul, kui viipe moodustamisel toimub nii sõrmede kui kogu käe või käte liikumine, oluline liikumise markeerimise koht transkriptsioonis (ROHELINE, MOOS, PÄEV jne). 
Tabel 3. Liigutuskireemid

\begin{tabular}{|c|c|c|}
\hline Sümbol & Liigutus & Näited \\
\hline$\wedge$ & üles & HOMMIK \\
\hline V & alla & EMA \\
\hline $\mathrm{N}$ & üles-alla & LAUPÄEV \\
\hline$>$ & paremale & PALAV \\
\hline$<$ & vasakule & ISA \\
\hline Z & küljelt küljele & SININE \\
\hline$->$ & enda poole & MULLE (ANDMA) \\
\hline$<-$ & endast eemale & VIIMA \\
\hline$-><-$ & $\begin{array}{l}\text { enda poole ja endast } \\
\text { eemale }\end{array}$ & KIIKUMA \\
\hline (o & sisenev & ÖÖ \\
\hline$><$ & pöörduv & OLEKS, KÜLM \\
\hline$\%$ & eralduv & ERI, LAHUTUS, KUUSK \\
\hline$\sim$ & vahelduv & DETSEMBER, MÕNIKORD \\
\hline+ & ristuv & ÕNNETUS, HAAVATUD \\
\hline() & ühenduv, haarav & VÕTMA, KINNI \\
\hline$x$ & kontakt & KOOS \\
\hline C & ringikujuline & AASTA, AEG, PUNANE \\
\hline W & $\begin{array}{l}\text { käänduv, keeramine, } \\
\text { pööramine }\end{array}$ & PEREKOND, KORTER, KÜLA \\
\hline G & painutus & VÄÄNAMA, KUMMARDAMA \\
\hline$U$ & avanev & PÜHAPÄEV \\
\hline$E$ & sulguv & TALLINN \\
\hline /:1 & pudenev & LIIV, RAHA \\
\hline * & väristamine & KARTMA \\
\hline $\mathrm{D}$ & kaarjas & HILJEM, MÄGI \\
\hline$S$ & looklev & MERI, TEE, RALLI \\
\hline.-- & katkestatud liigutus & VIHM \\
\hline
\end{tabular}

Tabel 4. Käte omavaheline suhe kahekäeviibetes

\begin{tabular}{|l|l|l|}
\hline Sümbol & Käte suhe & Näited \\
\hline$\|$ & kõrvuti & NAABER, KAASLANE, DETSEMBER \\
\hline$=$ & üks käsi teise kohal & ÕHTU \\
\hline$\left.\right|^{\wedge}$ & üks käsi teise taga & JÄRJEKORD \\
\hline $\mid()$ & ühenduses & KIIRABI \\
\hline $\mid(0$ & üks käsi teise sees & TUBA \\
\hline $\mid x$ & omavahel kontaktis & TÕLK \\
\hline $\mid+$ & risti & KALA \\
\hline
\end{tabular}


Kahekäeviibete puhul peame oluliseks tingimata ära näidata ka käte omavaheline suhe, kuigi seda ei peeta eraldiseisvaks kireemiks. Kui viipe moodustuskohaks on tugikäsi, siis soovitame märkida käte omavaheline suhe ära viipe kohatähise järel tabelis 4 toodud sümbolite abil.

\subsection{Sümbolite kasutamise reeglid ja valemid}

Viibete märkimisel järgitakse kindlaid järjekorrareegleid. Kõigepealt esitatakse käekuju koos sõrmede liikumise ning peopesa ja sõrmede orientatsiooniga, seejärel viipe moodustamise koht ja liigutus. Kui käekuju või viipe moodustuskoht viipe moodustamise käigus muutub, märgitakse nurksulgudes ([]) lõplik käekuju ja koht (kus viipe sooritamine lõpeb).

1) Erinevate parameetrite tähistused märgitakse järjekorras: käekuju / peopesa orientatsioon, sõrmede orientatsioon / koht / liigutus, viiperuumi piirkond [lõplik käekuju / lõplik soorituskoht].

2) Kahekäeviibete puhul märgitakse alati esimesena aktiivne käsi. Tavaliselt on selleks parem käsi.

3) Kui kahekäeviibete puhul pole eraldi märgitud koha sümbolit, siis on viipe sooritamise kohaks (nn manuaalne lokatsioon) teisena märgitud käevorm. Manuaalse lokatsiooni korral näitab liigutus domineeriva käe liikumist.

Kasutades sümboleid, kus K tähistab kohta, KK käekuju, SO sõrmede orientatsiooni, PO peopesa orientatsiooni, L liigutust ja S käte suhet, võib kireemide ülesmärkimise reegleid väljendada alljärgnevate valemitega:

1) ühekäeviibe, kus käekuju või moodustuskoht muutub: KK / PO SO / K / L [ KK / PO SO / K] (vt joonis 4: TEATAMA);

2) ühekäeviibe, kus käekuju või moodustuskoht ei muutu: KK / PO SO / K / L (vt joonis 4: PUNANE, EMA);

3) kahekäeviibe, mõlemad käed on aktiivsed: 2 KK / PO SO / S / K / L [] (vt joonis 4: ROHELINE, TUME);

4) kahekäeviibe, passiivne käsi on viipe moodustamise kohaks: KK / PO SO/ S / KK / PO SO / L [] (vt joonis 4: PRUUN).

Kui viipes sooritatakse samaaegselt mitme liigutuse kombinatsioon (nt EILE kaarjas liigutus endast eemale; ROHELINE - eraldumine ülevalt alla), siis märgitakse ära mõlemad liigutused, kusjuures liigutuste tähistuste järjekord ei ole määrav. 


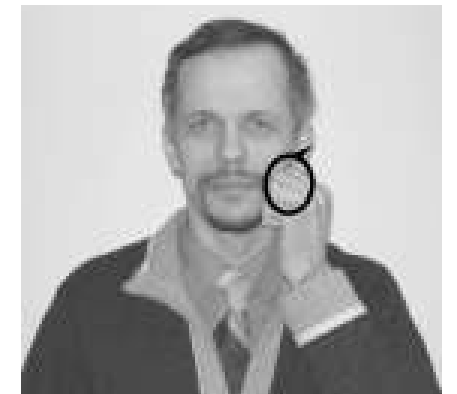

PUNANE

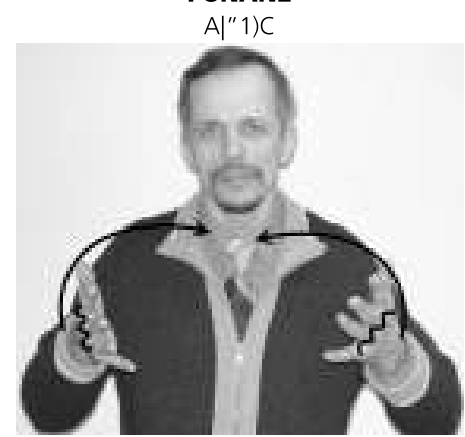

ROHELINE

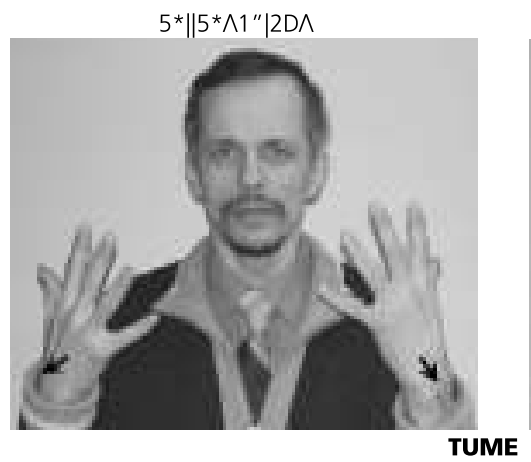

5|| $5 \mid " 1 / 2 / O N[5: \| 5: \wedge 1]$

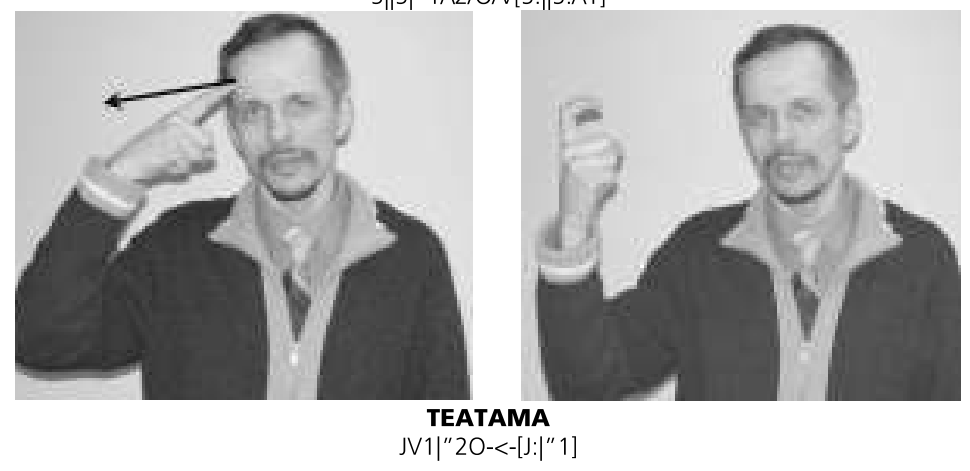

Joonis 4. Viibete ja nende transkriptsiooni näiteid

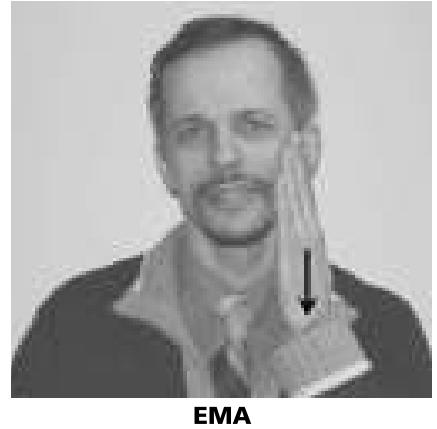

EMA

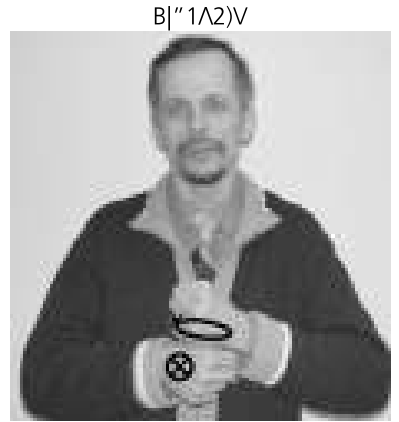

PRUUN

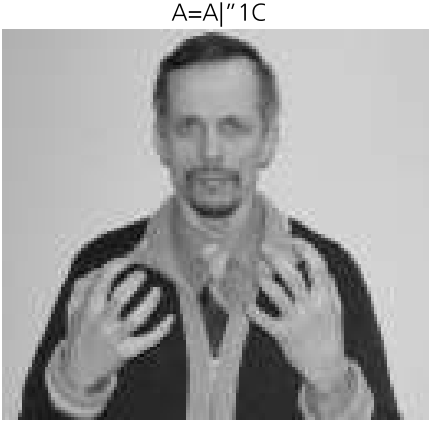




\section{Mõnedest viipekeelte semantika, morfoloogia ja süntaksi kirjeldamise põhimõtetest}

Ülaltoodud sümbolid ja reeglid võimaldavad kirjeldada viibete ülesehitust ja fikseerida nende moodustusviisi. Alljärgnevalt on toodud mõned reeglid, mille abil kirjeldada eesti keeles viipekeelte semantikat ning grammatilist ülesehitust. Reeglite koostamisel toetuti R. Sutton-Spence'ile ja B. Woll'ile (2003), kuid nende poolt märgitut on kohandatud eesti viipekeele järgi.

1. Viipe tähenduse märkimiseks kasutatakse algvormis ja suurte tähtedega kirjutatud eestikeelset vastet (MAGAMA).

2. Kui viipele pole võimalik leida ühesõnalist eestikeelset vastet, kasutatakse selle tähenduse edasiandmiseks mitut omavahel sidekriipsuga ühendatud sõna. Sidekriips viitab sellele, et tegemist on ühe viipega (EIMEELDIMA, MINA-KÜSIMA-SINA).

3. Verbi reduplikatsiooni tähistamisel kasutakse kahte võimalust: märgitakse korduva liigutusega väljendatud tegevuse tähendus (OOTAMAKAUA-AEGA) või rõhutatakse liigutuse kordamist, lisades selle eestikeelsele vastele kolm plussi (KOPUTAMA+++).

4. Sõrmendatud sõna kirjutatakse väikeste tähtedega, mis ühendatakse sidekriipsudega, nt k-o-e-r.

5. Viipega kaasnev pea liikumine või näoilme kirjeldus kirjutatakse viibet tähistava sõna kohale. Joon märgib seda, millal sõna või lause ütlemise ajal vastav mittekäeline komponent ilmnes.

\section{kissis silmad}

UNISTAMA

Vajadusel võib kasutada ka lühendeid, mis viitavad teatud tüüpi lausete juurde kuuluvale miimikale ja kehakeelele, nt

küs - küsilause näoilme ja pea liikumine, mis võivad erinevate küsimuste puhul olla järgmised:

• kas-küsimused või küsimärgi viipega markeeritud küsimused - kulmud tõstetud, silmad suured, keha ja pea ettepoole kallutatud; õlad võivad olla tõstetud;

- eriküsimused (inglise keeles $w h$-küsimused) - kulmud kortsus, pea kallutatud, keha võib olla ettepoole kaldus, õlad võivad olla tõstetud; - retoorilised küsimused - kulmud tõstetud, pea võib olla kallutatud või raputatakse kergelt;

ei - eitava lausega kaasnev külmunud näoilme või silmade kõõritus, pearaputus küljelt küljele;

$\mathrm{n}$ - neutraalne näoilme, kulmud tõstetud, pea kallutatud, jutustavale lausele omased mittekäelised elemendid;

kl - käsklause, otsene silmside sellega, kellele lause suunatud, tardunud miimika;

tl - tingimuslause, kulmud tõstetud, pea kaldus, võimalikud on nii väike paus, kui silmside vahetus;

pn - peanoogutus;

kk - kulmukergitus;

$\mathrm{kr}$ - kulmukortsutus. 
Viipekeelte grammatikas on väga oluline roll viipe paigastamisel ja sellele osutamisel viiperuumis. Kui referenti tähistav viibe on viiperuumis kohale asetatud, siis võib edasises tekstis osutada vaid sellele kohale viiperuumis (nt Minu pojad on kurdid. Nad on 5 ja 8 aastat vanad. - kui mõlemaid poegi tähistavad viiped on viiperuumis paigastatud, siis järgneva lause viiplemisel osutatakse vaid n-ö poegade asukohale viiperuumis).

6. Osutamise tõlkimisel kasutatakse kahte võimalust:

- antakse edasi lause tähendus ja see pannakse kirja teisi reegleid arvestades (SINA ARMASTAMA TEDA);

- osutavat viipemärki tähistatakse sõnaga "osutus" ning osutatava piirkonna märkimisel kasutatakse viiperuumi piirkondade numbreid (vt joonis 5). Juhul, kui osutust märgitakse lähtuvalt sellest, missugust grammatilist tähendust osutus kannab (osutus isikule), kannab osutus alaindeksit - vastavalt osutus ${ }_{1,2,3}$ (ARMASTAMA osutus ${ }_{2}$ ).

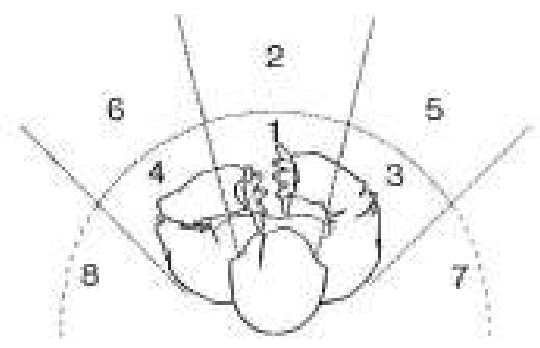

Joonis 5. Viiperuumi piirkonnad

7. Viipekeelse lause osi seovad omavahel pausid. Pausi lauses märgitakse kahe kaldkriipsuga $(/ /)$.

8. Klassifikaatorit märgitakse lühendiga KLA. Vajadusel võib eristada ka inimese klassifikaatorit (in-KLA). Eri kuju ja suurusega referente tähistavate viibete paigastamiseks või referentidele viitamiseks kasutatavaid spetsiifilisi käekujusid, mida nimetatakse proformideks (lühend PRO). Kuna proformid moodustatakse alati ühe käega ning nad pole kehaga seotud, siis saab neid viiperuumis paigastada, ümber paigutada, korrata ja liigutada. Selline liikumisvabadus ei ole täisviibete puhul võimalik, seega esineb proform asesõna funktsioonis. Proformid sisaldavad klassifikaatoreid, mis väljendavad referendi kuulumist kindlasse ühiste tunnustega gruppi (Sutton-Spence, Woll 2003: 43-44). Uurijad C. Lucas ja C. Valli (2003: 47-48) nimetavad klassifikaatoriks käekuju, mis lauses predikaadi moodustamiseks kombineerub koha, suuna, liikumise ja mittekäeliste vahenditega.

9. Sõrmendviipeid tähistatakse sümboliga \# viibet tähistava sõna alguses.

Viibete fikseerimisel piltidena, kasutakse ülaltoodud liikumiste markeerimisel järgmisi joonetüüpe (vt joonis 6).

Nende joontetüüpide ja noolte abil on võimalik vastavalt vajadusele kujundada mitmeid erinevaid nooli ja märkida erinevaid liikumissuundi (vt joonis 7). 
neutraalse iseloomuga liikumine noolega näidatud suunas

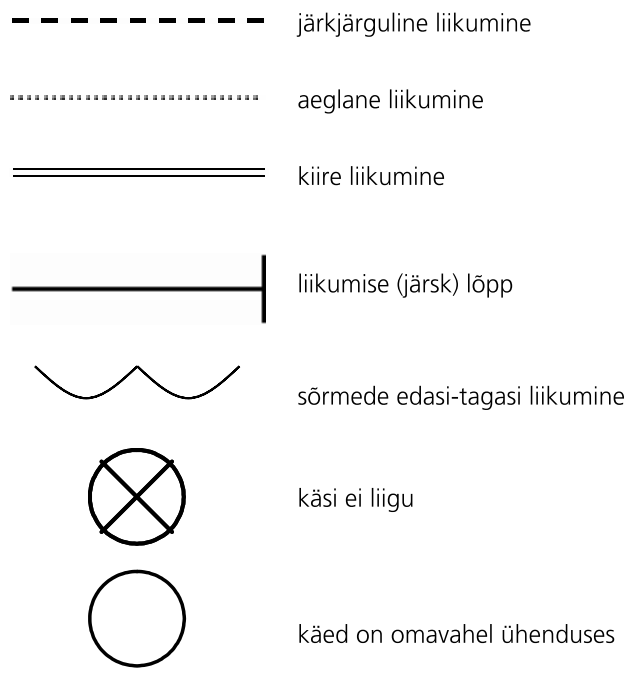

Joonis 6. Liigutuste märkimine pildile (noole värv tähendust ei erista, tumeda tausta korral võib vajadusel kasutada ka valget värvi nooli)

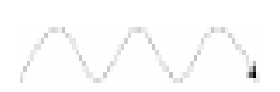

aeglane üles-alla sikk-sakk vasakult paremale

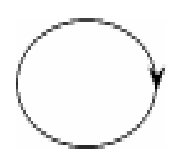

ringliigutus

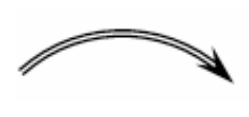

kiire kaarjas liigutus

Joonis 7. Näiteid liigutuste markeerimiseks kasutatavatest joonetüüpidest

\section{Lõpetuseks}

Käesolev artikkel andis lühiülevaate viipekeelte kiroloogiast ning maailmas kasutusel olevatest erinevatest transkriptsioonisüsteemidest. Kirjeldati eesti viipekeele kireeme ja nende tähistamiseks kasutatavaid sümboleid ning esitati sümbolite kasutamiseks vajalikud reeglid ja valemid. Anti ülevaade ka maailmas kasutatavatest viipekeelte semantika, morfoloogia ja süntaksi ülesmärkimise põhimõtetest ning nende rakendamise võimalustest eesti viipekeele kirjeldamisel. 


\section{Kirjandus}

Boyes Braem, Penny 1995. Einführung in die Gebärdensprache und ihre Erforschung. Hamburg: Signum-Verlag.

Brennan, Mary 1990. Word formation in BSL. University of Stockholm.

Laiapea, Vahur; Miljan, Merilin; Sutrop, Urmas; Toom, Reigina 2003. Eesti viipekeel. Eesti Keele Sihtasutus.

Laiapea, Vahur 1992. Mis on eesti viipekeel. - Akadeemia 10, 2098-2136.

Liddell, Scott K.; Johnson, Robert E. 2000 [1989]. American Sign Language. The phonological base. - Linguistics of American Sign Language. An Introduction. Ed. by Clayton Valli, Ceil Lucas. Washington D.C.: Gallaudet University Press, 267-306.

Moy, Anthony 1990. A Psycholinguistic Approach to Categorizing Handshapes in American Sign Language. Is $\left[\mathrm{A}_{\mathrm{s}}\right.$ ] an Allophone of /A/? - Sign language research. Theoretical issues. Ed. by Ceil Lucas. (Proceedings of the International Conference, Theoretical Issues in Sign Language Research, II, May 18-21, 1988 at Gallaudet University.) Washington, DC: Gallaudet University Press, 346-357.

Prillwitz, Siegmund; Wudtke Hubert 1989. Gebärden in der Vorschulischen Erziehung. Gehörloser Kinder. Universität Hamburg. Hamburg.

Püvi, Egle 2005. Eesti viipekeele keroloogiasüsteemi kirjeldus. Bakalaureusetöö. Tartu Ülikool.

Rissanen, Terhi 1985. Viittomakielen perusrakenne. Publications of University of Helsinki. Department of General Linguistics, No. 12.

Sandler, Wendy 1989. Phonological Representation of the Sign. Linearity and Nonlinearity in American Sign Language. Dordrecht-Holland/Providence RI- U.S.A.: Foris Publications.

Senghas, J. Richard; Monaghan, Leila 2002. Signs of Their Times. Deaf Communities and the Culture of language. - Annual Review Anthropology 31, 69-97.

Stokoe, William C.; Casterline, Dorothy C.; Croneberg, Carl G. 200o [1976]. Introduction from A Dictionary of American Sign Language. - Linguistics of American Sign Language. An Introduction. Ed. by Clayton Valli, Ceil Lucas. Washington D.C.: Gallaudet University Press, 243-258.

Sutton-Spence, Rachel; Benice Woll 2003. The Linguistics of British Sign Language. An Introduction. United Kingdom: Cambridge University Press.

Valli, Clayton; Lucas, Ceil 200o. Linguistics of American Sign Language. An introduction. Washington D.C.: Gallaudet University Press. 


\section{ESTONIAN SIGN LANGUAGE TRANSCRIPTION}

\section{Reigina Toom, Monika Trükmann, Liivi Hollman}

Estonian Sign Language (ESL) is the native language for approximately 1,500 Estonian Deaf people. Like other sign languages, ESL has no written form. In the history of ESL research, different transcription systems have been used. The system introduced here is based on the one used at the University of Tartu. The structure of the transcription system follows the example of W. Stokoe's notation system and its expansions. Cherems of ESL are introduced and symbols for 38 hand forms, 26 locations, and 26 different movements are presented. All symbols are easy to use with any computer program. For the detailed transcription of the signs, the symbols for the palm and finger orientation as well as the relationship between the two hands are given. Finally there is provided an overview of the sign language glossing rules which are used in different sign language researches and which form a basis for glossing sign language grammar and semantics.

Keywords: sign language, language area studies, methods and tools, Estonian Sign Language

Reigina Toom (1958) on lõpetanud Tartu Ülikooli eripedagoogika osakonna surdopedagoogika eriala. Töötab Tartu Ülikoolis alates 1989. a. Kaitses magistritöö Tartu Ülikoolis eripedagoogika erialal 2002. a. On uurinud eesti viipekeelt, kurtide kogukondlikku kultuuri, viipekeeletőlkide professiooni kujunemist.

reigina.toom@ut.ee

Monika Trükmann (1976) on lõpetanud Tartu Ülikooli eripedagoogika osakonna. Alates 2002. a magistriüliöpilane. On uurinud viipekeelset tõlget õppesituatsioonis, magistritöö raames uurib ajasuhete väljendamist eesti viipekeeles.

monika.trykmann@mail.ee

Liivi Hollman (1971) on lõpetanud Tartu Ülikooli eripedagoogika osakonna. Kaitses magistritöö Tartu Ülikoolis eripedagoogika erialal 2002. a. On uurinud tõlkeprotsessi ja tõlgi käitumist tõlkesituatsioonis, kus üheks töökeeleks on viipekeel. Töötab Eesti Kurtide Liidus ning Eesti Keele Instituudis. Alates 2005. aastast Tartu Ülikooli üldkeeleteaduse doktorant, uurimistöö teemaks värvinimed eesti viipekeeles.

liivi@ead.ee 